\title{
Per 10 High Powered Fields
}

National Cancer Institute

\section{Source}

National Cancer Institute. Per 10 High Powered Fields. NCI Thesaurus. Code C158699.

A unit of measurement of the number of entities per unit of area equal to ten high powered fields. 